TESTIMONIOS DE AFECTO Y AMISTAD

Revista Atlántica-Mediterránea 22, pp. 11-41

BIBLID [2445-3072 (2020) 22, 1-443]

https://doi.org/10.25267/rev_atl-mediterr_prehist_arqueol_soc.2020.v22.07

\title{
CARTA DE AGRADECIMIENTO
}

\section{Aurora HIGUERAS-MILENA CASTELLANO}

IAPH - Centro de Arqueología Subacuática, Cádiz

Correo electrónico: aurora.h.castellano@juntadeandalucia.es

Cuando en 1986 se celebraron en San Fernando los II Encuentros de Historia y Arqueología Antonio Sáez Espligares, director entonces del Aula de Historia de la Fundación Municipal de Cultura, fue uno de los responsables de traer a los mejores profesionales de la disciplina a un foro donde compartir los resultados de las investigaciones de Arqueología Submarina en la Bahía de Cádiz (Olga Vallespín , Juan Ramón Ramírez, Ramón Corzo, María Sanz Nájera), así como de conseguir despertar gran interés por parte de la prensa que publicó numerosas noticias durante los días que duraron las jornadas, y como anécdota, recogía el periódico la preocupación de Antonio, ante la dificultad del conseguir películas o diapositivas sobre el tema.

Los tiempos han cambiado muchísimo, pero si una imagen, aún ahora, vale más que mil palabras, cada una de las fotografías en $35 \mathrm{~mm}$, - color o B/N-, que retrataron las actuaciones arqueológicas de aquellos años es única e irrepetible. Y si hay alguien que ha sido desde siempre consciente de la importancia de la fotografía como técnica documental, ese ha sido Antonio, con su cámara colgada al cuello, ilustrando yacimientos, hallazgos e intervenciones. La documentación gráfica de su archivo debe contener la historia de las actuaciones arqueológicas realizadas en La Isla, momentos únicos en numerosos yacimientos de la provincia.

Hablamos de tiempos en los que no existía la inmediatez, facilidad y cercanía de las redes sociales para concienciar o denunciar. Por ello, cobra doble valor ahora su sentido de la responsabilidad, el interés y celo por el Patrimonio que ha llevado siempre a Antonio a implicarse más allá de su trabajo para la administración. Ha actuado como director, técnico de laboratorio, de restauración, bibliotecario, investigador, profesor, guía... todo salpicado con varias mudanzas y restructuraciones, con lo que eso supone para un Museo.

Pero, faltaríamos al rigor, y también a la justicia, si solo nos centráramos en su labor profesional. Es momento de alabar su gran dimensión humana, su suave carácter y trato cercano. Desde el principio y hasta su jubilación, ha ofrecido siempre una sonrisa de complicidad investigadora, asesorando tanto a los profesionales, como a los principiantes (incluso en el trance de estabilizar bolas de cañón).

He tenido el privilegio de participar en dos importantes intervenciones arqueológicas en San Fernando: en la Rotonda de Benjamín López junto a Vicente Castañeda, y en el complejo de Pery Junquera, junto
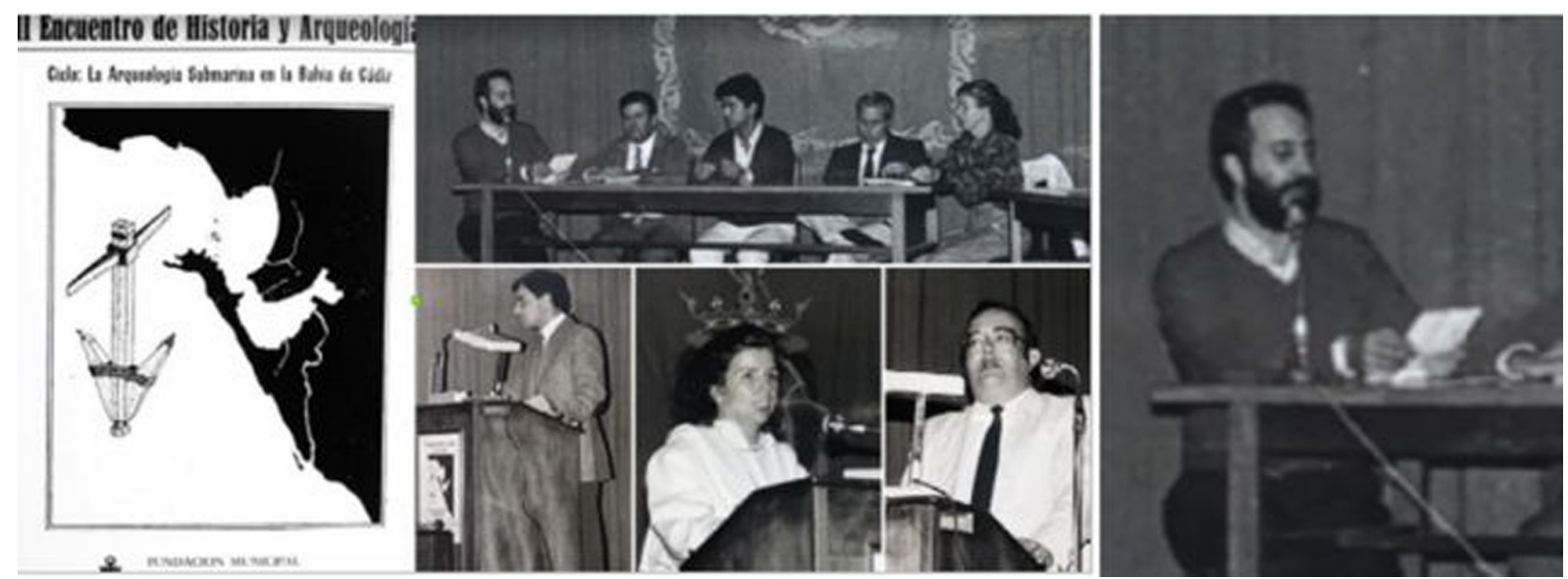

Figura 1. Imagen de los conferenciantes y del coloquio presentado por Antonio. Fotografías del Archivo Municipal de San Fernando. 

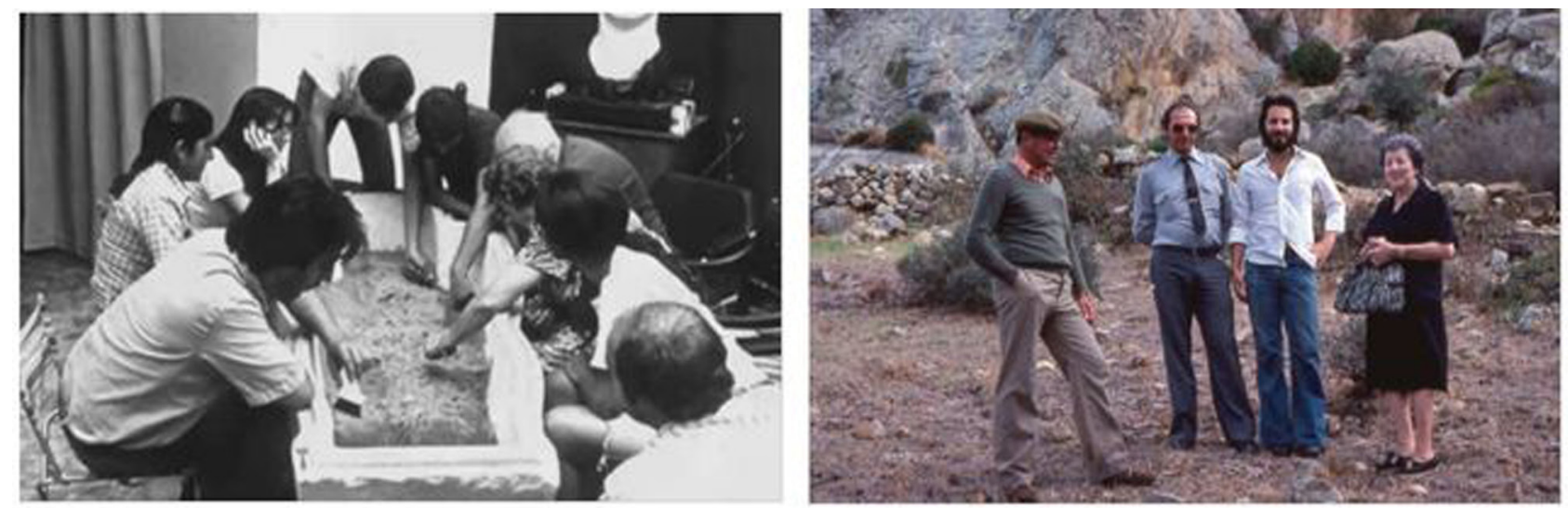

Figura 2. Testigo de momentos emblemáticos de la arqueología, colaborador del Museo de Cádiz. Con Doña Concha (Tajo de Las Figuras).

a nuestra querida Beatriz González Toraya. Siempre contamos con su buena disposición, sus consejos, y en la medida de sus posibilidades, las puertas abiertas de las instalaciones del Museo para estudios de materiales.

No podemos terminar este pequeño homenaje de otra forma que no sea hablando de futuro. Si el legado profesional ha sido muy importante y fundamental para el Patrimonio Arqueológico de La Isla, hay que resaltar que nos ha dejado un legado aún mayor para el futuro: su hijo Antonio. Profesor de la Universidad de Sevilla, es ya uno de los investigadores más admirados de la esfera profesional, que ha heredado de sus padres, una excepcional calidad humana.

Un fuerte abrazo.

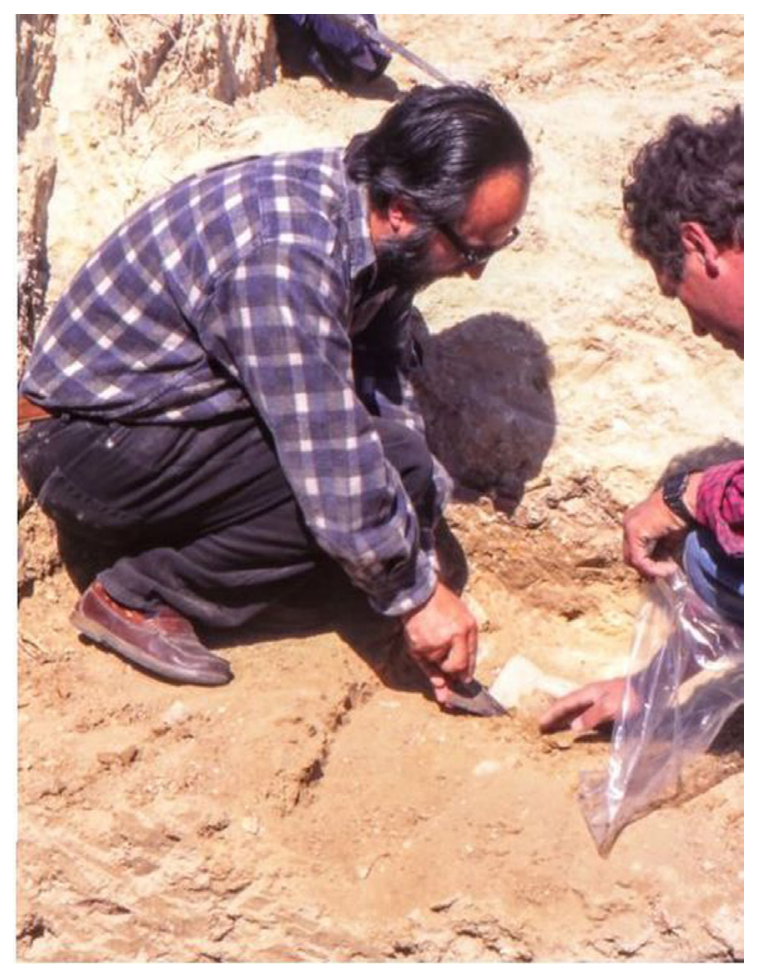

Figura 3. Colaborando en la Rotonda Benjamín López, 1995. 